\title{
A preliminary integrated genetic map distinguishes every chromosome pair and locates essential genes related to abiotic adaptation of Crassostrea angulata/gigas
}

Ismael Cross', Silvia Portela-Bens ${ }^{1}$, Aglaya García-Angulo ${ }^{1}$, Manuel A. Merlo ${ }^{1}$, María E. Rodríguez ${ }^{1}$ Thomas Liehr ${ }^{2}$ and Laureana Rebordinos ${ }^{1 *}$ (D)

\begin{abstract}
Background: The re-sequencing of C. angulata has revealed many polymorphisms in candidate genes related to adaptation to abiotic stress that are not present in C. gigas; these genes, therefore, are probably related to the ability of this oyster to retain high concentrations of toxic heavy metals. There is, in addition, an unresolved controversy as to whether or not C. angulata and C. gigas are the same species or subspecies. Both oysters have 20 metacentric chromosomes of similar size that are morphologically indistinguishable. From a genomic perspective, as a result of the great variation and selection for heterozygotes in C. gigas, the assembly of its draft genome was difficult: it is fragmented in more than seven thousand scaffolds.

Results: In this work sixty BAC sequences of C. gigas downloaded from NCBI were assembled in BAC-contigs and assigned to BACs that were used as probes for mFISH in C. angulata and C. gigas. In addition, probes of $\mathrm{H3}, \mathrm{H} 4$ histone, 185 and 55 rDNA genes were also used. Hence we obtained markers identifying 8 out the 10 chromosomes constituting the karyotype. Chromosomes 1 and 9 can be distinguished morphologically. The bioinformatic analysis carried out with the BAC-contigs annotated 88 genes. As a result, genes associated with abiotic adaptation, such as metallothioneins, have been positioned in the genome. The gene ontology analysis has also shown many molecular functions related to metal ion binding, a phenomenon associated with detoxification processes that are characteristic in oysters. Hence the provisional integrated map obtained in this study is a useful complementary tool for the study of oyster genomes.

Conclusions: In this study 8 out of 10 chromosome pairs of Crassostrea angulata/gigas were identified using BAC clones as probes. As a result all chromosomes can now be distinguished. Moreover, FISH showed that $\mathrm{H3}$ and $\mathrm{H} 4$ co-localized in two pairs of chromosomes different that those previously escribed. 88 genes were annotated in the BAC-contigs most of them related with Molecular Functions of protein binding, related to the resistance of the species to abiotic stress. An integrated genetic map anchored to the genome has been obtained in which the BAC-contigs structure were not concordant with the gene structure of the C. gigas scaffolds displayed in the Genomicus database.
\end{abstract}

Keywords: Crassostrea angulata, Crassostrea gigas, Chromosome mapping, Abiotic adaptation, Aneuploidy, Chromosome markers

\footnotetext{
* Correspondence: laureana.rebordinos@uca.es

${ }^{1}$ Area de Genética. Facultad de Ciencias del Mar y Ambientales, Universidad

de Cádiz. Polígono Río San Pedro, 11510 Puerto Real, Cádiz, Spain

Full list of author information is available at the end of the article
}

(c) The Author(s). 2018 Open Access This article is distributed under the terms of the Creative Commons Attribution 4.0 International License (http://creativecommons.org/licenses/by/4.0/), which permits unrestricted use, distribution, and reproduction in any medium, provided you give appropriate credit to the original author(s) and the source, provide a link to the Creative Commons license, and indicate if changes were made. The Creative Commons Public Domain Dedication waiver (http://creativecommons.org/publicdomain/zero/1.0/) applies to the data made available in this article, unless otherwise stated. 


\section{Background}

The worldwide production of oysters is 5.15 million tons/year, second only by weight to carp and other cyprinids [1]; the genera Ostrea and Crassostrea (Ostreidae) make up most of the species of commercial interest. The Pacific oyster Crassostrea gigas (Thunberg, 1793), in particular, is now one of the most important bivalves produced commercially throughout the world. Global annual production volume is uncertain, owing to taxonomic confusion in reports from China and other countries [2], but is conservatively estimated at 626,000 metric tons in 2016 [1]. Another Crassostrea species of interest is the Portuguese oyster, C. angulata (Lamarck, 1919); this species is an edible cupped oyster of major commercial importance and wide geographic distribution. It is assumed to be native to the Northwest Pacific region and has been introduced into many countries around the world [3]. C. angulata was a species of considerable commercial importance in Europe up to the early 1970's, but serious mortalities in those years almost wiped out the Portuguese oyster from Europe. As a result, the extent of remaining C. angulata populations is poorly known. Recent studies have shown that the Fujian oyster that has been harvested and cultivated for more than 2000 years in coastal river mouths and estuaries of southern China is actually C. angulata. The production of this Fujian oyster accounts for about 50\% of total oyster production in China. At the present time, according to some authors, $C$. angulata should be considered as a subspecies of $C$. gigas [3] . Because of the commercial importance of Crassostrea species, a number of breeding programs have been initiated over the years, and substantial genetic and genomic knowledge has been accumulated [4-9], although some important characteristics of genome organization remain unclear.

Oysters have a diploid number of 20 chromosomes [10]. Their karyotypes show most of their chromosomes to be submetacentric or metacentric, that are of similar size and morphologically indistinguishable; molecular markers are needed to differentiate them, mainly because of the many instances of aneuploidy occurring in natural populations of mollusks [11]. To study the evolution and phylogenetic relationships among oyster species, it is necessary to characterize the chromosomes individually, and particular regions of them. The C-banding and restriction techniques, as well as the study of Ag-NOR and cytogenetic markers, have been applied to several different species of oysters describing several cytogenetic markers that allow identify chromosome pairs in some cases [12-17].

The introduction of the fluorescence in situ hybridization (FISH) technique opened the possibility of studying more deeply inside the chromosomes than had been possible before. FISH is also a powerful tool for defining the cytogenetic location and relative order of DNA sequences, thereby anchoring the genome sequence to the chromosomes. It has been successfully used to integrate genetic and cytogenetic maps in many plants and animals [18-22]. During the past two decades, there have been many FISH studies, based on species of interest in aquaculture, that have contributed to a better understanding of these genomes. The FISH technique has greatly facilitated comparative genomic analysis to study the evolution of genomes [23-27]. In oysters, analysis has been focused on the study of repetitive and multigene families [28-31].

Histones are basic structural proteins of the nucleosomes and, in eukaryotic organisms, are essential for DNA packaging. This group is subdivided into five protein classes, termed $\mathrm{H} 1$, located bound to the "linker DNA" region between nucleosomes, and $\mathrm{H} 2 \mathrm{~A}, \mathrm{H} 2 \mathrm{~B}, \mathrm{H} 3$, and $\mathrm{H} 4$, located in the core of the nucleosomes. The histones have functional consequences, as trans-acting regulatory factors, because the transcription machinery must gain access to their specific binding sites at the DNA level [32]. Thus, knowing its location can help to understand its chromosome organization and evolution. In addition, the histone genes have been used as markers for taxonomic differentiation [33-36].

Going beyond the controversy of whether $C$. angulata and $C$. gigas are different species or subspecies, the whole genome re-sequencing of $C$. angulata showed many polymorphisms in candidate genes related to adaptation to abiotic stress that are not present in $C$. gigas, and hence are probably related to the ability of this oyster to retain high concentrations of toxic heavy metals [37].

Genetic maps are essential tools, useful for mapping quantitative-trait loci in marker-assisted selection, positional cloning, and genome assembly. In oyster species, linkage and physical maps have been described [38, 39]. Although the publication of the C. gigas genome draft is considered a great step forward in the knowledge of these organisms, at the present time the genome is assembled only to a level below that of the scaffold $(\mathrm{N} 50=31,239)$ due to the complexity of its genome, its variation and selection for heterozygotes [40]; currently more than seven thousand scaffolds have been found. Mapping using BAC-FISH probes has allowed progress, in a straightforward and easy way, to final assembly and mapping of genes in their chromosomes. However, cytogenetic mapping of clones with large inserts is at present limited to a few species of interest for aquaculture $[18,23,26,27]$. Knowing from gene libraries the position of clones that contain large inserts presents important advantages, since it is not limited to the location of repetitive DNA and allows the localization of multiple probes for each chromosome, thereby raising the number of markers per chromosome karyotype and in each 
species. From these clones, the inserts can be sequenced with next generation sequencing techniques, thereby enabling us to know the position and insert genes in the library hybridized in a straightforward manner [23, 26]. Moreover, the application of FISH based on the use of bacterial artificial chromosome clones (BAC) as probes provides an efficient approach for anchoring linkage and genomic data in the physical chromosomes [41]. In mollusks, genetic and cytogenetic maps have been integrated using this BAC-FISH approach in the Zhikong Scallop, Chlamys farreri, selecting markers from microsatellitebased linkage maps from a BAC library [18]. In oysters, to date, this approach has been applied only in the American oyster $C$. virginica, using inserts from a library based on phage P1 [39].

In order to gain insight into the genomes and chromosomes of C. angulata/gigas, an integrated genetic map, based on BACs and multigene families, has been designed with the aim of providing chromosomal markers and that could be anchored reliably to the sequenced genome of the species.

\section{Material and methods}

Selection and BAC clones getting from a C. gigas genetic library

Sixty BAC sequences downloaded from the National Center for Biotechnology Information (NCBI: http:// www.ncbi.nlm.nih.gov/) (Acc. numbers from GU207404 to GU207462, and GU324325) were assembled with SeqMan software (Lasergene, DNASTAR). These sequences correspond to different BAC clones from a genetic library of $C$. gigas belonging to the Clemson University Genomics Institute (CUGI). From the contigs obtained (from now on named BAC-contigs), one BAC per contig and a single BAC (not included in any contig) were selected and ordered from the CUGI (Additional file 1: Table S1). The BAC clones were then mapped on $C$. angulata and $C$. gigas chromosomes by means of 2- and multi-color FISH.

\section{Probes and labelling for FISH}

DNA was extracted from BACs using the BACMAX ${ }^{\mathrm{tm}}$ DNA purification kit (Epicentre), following manufacturer's instructions. For 2-color FISH, probes were labeled using the DIG/BIO Nick Translation Mix kit (Roche Molecular Biochemicals). In order to label 5S rDNA and 18S rDNA multigene families, PCR amplifications with biotin-16dUTP or digoxigenin-11-dUTP (Roche Molecular Biochemicals) were made [28]. For the H3 histone gene the primers H3F (5'-CGTAAATCCACTGGAGGCAAGG3') and H3R (5'-GGATGGCGCACAGGTTGGTGTC$\left.3^{\prime}\right)$ were used [42]. The $\mathrm{H} 4$ histone genes were amplified by primers H4-F (5'-TGAGAGATAACATCCAG GGTATCAC-3') and H4-R (5' - CTCTTGAGGGCGTA GACAACGTCCAT-3').

\section{Chromosome preparations and FISH mapping}

Samples of $C$. angulata of $2-3 \mathrm{~cm}$ in length were obtained from naturally-occurring populations located in the mouth of the River Guadalquivir, in Sanlúcar de Barrameda (Cádiz, Spain). C. gigas samples came from the facilities of a local aquaculture company. After feeding the oysters with phytoplankton for several days, they were placed in beakers and cultured for $8 \mathrm{~h}$ in colchicine. The gills were then extracted and put under hypotonic shock conditions by incubating with $\mathrm{KCl} 0.4 \%$ for at least $1 \mathrm{~h}$. After that, they were transferred to fresh Carnoy for $1 \mathrm{~h}[28]$.

Twelve BACs were used as probes to hybridize on $C$. angulata and C. gigas chromosomes using the FISH-BAC technique (Table 1; Additional file 1: Table S1). In addition, probes of $\mathrm{H} 3$ and $\mathrm{H} 4$ histones, $18 \mathrm{~S}$ and $5 \mathrm{~S}$ rDNA genes were also used to analyze their position in chromosomes relative to the hybridized BACs.

The 2-color FISH method used for BAC clones probes was performed following the protocol of García-Cegarra et al. [26]. Multiple-FISH (mFISH) was carried out as described in Portela-Bens et al. [23]. The 2-color FISH technique described by Cross et al. [28] was used to localize the $\mathrm{H} 3$ and $\mathrm{H} 4$ histone genes.

\section{Bioinformatic analysis of BAC clones}

The contigs containing hybridized BACs were annotated from the C. gigas genome draft, available at the NCBI [40]. The BAC-contig sequences were subjected to Blast search against $C$. gigas Whole-Genome shotgun contigs from NCBI/BLAST/blastn suite (from now on named Cg-contigs) (AFTI: Crassostrea gigas strain $05 \times 7-\mathrm{T}-\mathrm{G} 4-$ $1.051 \# 20$, whole genome shotgun sequencing project). In order to obtain genes from these Cg-contigs, a manual search of scaffolds (containing Cg-contigs) stored in the "EnsemblMetazoa C. gigas" database was conducted. To confirm the presence of this set of genes obtained after scaffolds data mining, the genes were then blasted (Blast2seqs) against every single BAC-contig; genes showing a $P$-value $<0.001$ and a coverage $>90 \%$ were then annotated. Next, using the genomic editor Apollo [43], and Geneious basic 5.6.5 (http://www.geneious.com), the results were individually tested and adjusted in the final editing process.

The study of functions in genome regions covered by the BAC-contigs was carried out using data mining techniques based on the information stored in the Gene Ontology (GO) database. After getting GO terms from genes annotated in the BAC-contigs (C. gigas EnsemblMetazoa) we have used the QuickGo browser (https:// www.ebi.ac.uk/QuickGO) to obtain GO terms found for each BAC-contig, and then analyzed the main Molecular Function carried out in those regions. Comparison charts from the Biological Process, Molecular Function and Cellular Component domains were also prepared. 
Table 1 List of contigs after assembling BAC sequences of Crassostrea gigas

\begin{tabular}{|c|c|c|c|c|}
\hline BACs - Acc. Numb. (GenBank) & BAC-hybrydyzed & BAC Size (bp) & Contig -Label & BAC-Contig Size (bp) \\
\hline GU207429 & Ba10606 & 158.090 & Contig-1 & 271.505 \\
\hline GU207449 & $\mathrm{Ba} 127 \mathrm{~B} 8$ & 134.205 & & \\
\hline GU207421 & $\mathrm{Ba} 21017$ & 164.533 & & \\
\hline GU207416 & Ва33М18 & 136.953 & & \\
\hline GU207407 & Вa3117 & 172.567 & & \\
\hline GU207433 & Ba58D2 & 133.199 & & \\
\hline GU207422 & Ba67A11 & 203.422 & & \\
\hline GU207441 & Ba91N8 & 162.424 & & \\
\hline GU207454 & Ba3D14 & 176.912 & Contig-2 & 254.895 \\
\hline GU207439 & Ba30A15 & 137.420 & & \\
\hline GU207409 & $\underline{\mathrm{Ba} 133 \mathrm{H} 22}$ & 143.744 & Contig-3 & 161.079 \\
\hline GU207424 & Ba183L3 & 161.003 & & \\
\hline GU207404 & $\underline{B a 13 P 13}$ & 152.407 & Contig-4 & 222.359 \\
\hline GU207443 & Ba181L20 & 124.416 & & \\
\hline GU207447 & Ba45N13 & 130.545 & & \\
\hline GU207453 & Ba98C1 & 143.273 & & \\
\hline GU207446 & Ba98123 & 114.800 & & \\
\hline GU207426 & $\underline{B a 17 L 12}$ & 119.765 & Contig-5 & 204.747 \\
\hline GU207445 & Ba172M23 & 130.127 & & \\
\hline GU207458 & Ba118P9 & 174.057 & & \\
\hline GU207462 & Ba80D21 & 123.070 & & \\
\hline GU207460 & Ba96Р24 & 132.147 & Contig-6 & 141.754 \\
\hline GU207420 & Ba17109 & 123.180 & & \\
\hline GU207448 & Ba107F17 & 123.528 & & \\
\hline GU207455 & $\underline{B a 45 B 21}$ & 138.330 & Contig-7 & 237.501 \\
\hline GU207406 & Ba147A6 & 132.499 & & \\
\hline GU207436 & Ba96110 & 126.652 & & \\
\hline GU207411 & $\underline{B a 18 I 16}$ & 164.184 & Contig-8 & 238.060 \\
\hline GU207450 & Ba8F15 & 117.743 & & \\
\hline GU207413 & $\underline{B a 102 L 1}$ & 122.190 & Contig-9 & 198.436 \\
\hline GU207442 & Ba151B13 & 139.968 & & \\
\hline GU207423 & Ba50J23 & 84.264 & & \\
\hline GU207459 & $\underline{B a 177 C 12}$ & 136.235 & Contig-10 & 195.233 \\
\hline GU207456 & Ba188K9 & 117.224 & & \\
\hline GU207412 & Ba50F9 & 130.402 & Contig-11 & 277.695 \\
\hline GU324325 & Ba57G5 & 149.919 & & \\
\hline GU207418 & Ba127F5 & 132.710 & Contig-12 & 132.710 \\
\hline
\end{tabular}

BACs in bold were hybridized by means of 2-color and multiple-color BAC-FISH technique

Finally, the structure of the BAC-contigs, obtained after annotation, and the information provided by the Genomicus database v25.01 using C. gigas as reference species [44], were compared. The object of this analysis is to test the concordance between, on the one hand, the C. gigas genome assembly and structure, available in $C$. gigas databases (EnsemblMetazoa C. gigas and Genomicus), and on the other, the BAC-contigs sequences. To carry out this analysis, a search was made for every gene annotated finally in BAC-contigs in the Genomicus database (using $C$. gigas genome as reference), and the scaffolds containing the annotated genes were scored. Then, for each BAC-contig, a map of scaffolds containing the genes was created. This information was used to compare the BAC-contig genetic 
structure obtained after annotation $v s$ the C. gigas scaffolds structure from $C$. gigas genomic databases.

\section{Results \\ BAC-FISH}

Sixty BAC sequences of C. gigas were downloaded from NCBI and assembled in BAC-contigs by means of Seq-Man software (Lasergene, DNASTAR). Eleven BACs from these contigs and one BAC more, not belonging to contigs (BAC-unitig), were used to carry out this study.

No differences in BAC-FISH results between C. angulata and $C$. gigas were found during the study. Results show three BACs hybridized in chromosome 2: 177C21, 50F9 and $102 \mathrm{~L} 1$ (Fig. 1). The last two are located in one arm of the chromosome. BAC $177 \mathrm{C} 21$ is located in the other arm, in subcentromeric position. Chromosome 3 contains the $\mathrm{H} 4$ histone gene and, in the same arm, the clones Ba17L12 and Ba18I16 are found co-localized. BAC Ba106O6 is located in chromosome 4 next to the $5 \mathrm{~S}$ rDNA genes. The $5 \mathrm{~S}$ rDNA genes are located in two chromosome pairs, 4 and 5, in C. angulata and C. gigas (Cross et al. 2005; Benabdelmouna et al. 2008); this BAC is located in a pericentromeric position, in a more internal position than $5 \mathrm{~S}$ rDNA. The BAC 3D14 is found in chromosome 5, next to another $5 \mathrm{~S}$ rDNA locus. Following these results, these two BACs allow chromosome 4 to be distinguished from chromosome 5 in these Crassostrea oysters studied (Table 2; Figs. 1 and 2). BAC $127 \mathrm{~F} 5$ is located in a pericentromeric position of chromosome pair 6. BACs 133H22 and 96P24 are located in chromosome pair 7; and the BACs $13 \mathrm{P} 13$ and 45B21 are in chromosome 8 . Of the 12 BACs hybridized, none is located in chromosomes 1 or 9. The 18S rDNA gene family is located in chromosome 10 [28].

$\mathrm{H} 3, \mathrm{H} 4$ and ribosomal genes (5S and $18 \mathrm{~S}$ ) probes were also hybridized by standard FISH protocol. The results showed that $\mathrm{H} 3$ and $\mathrm{H} 4$ co-localized in two pairs of chromosomes of medium size. One of them should be chromosome pair 3, as described in the preceding paragraph, by means of FISH-BAC protocols. The additional signal of hybridization was observed in a second chromosome pair of medium-size. Analysis of the relative position of histone genes and ribosomal genes showed that they are not co-localized in either the Japanese or Portuguese oysters (Figs. 1 and 2).

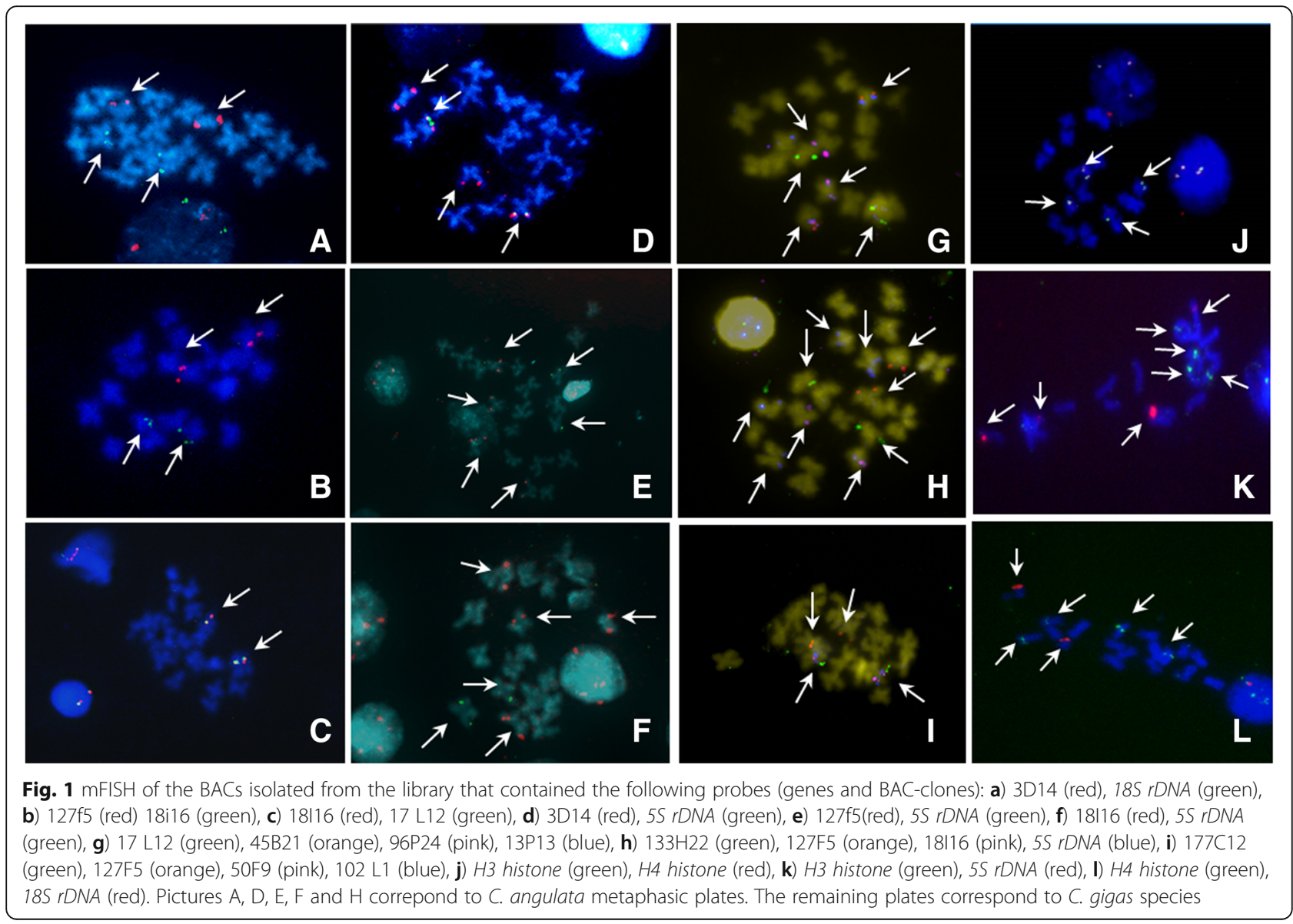


Table 2 Summary of results obtained after hybridization of BACs by two- and multi-color FISH technique and annotation of BAC-contigs and a BAC-unitig

\begin{tabular}{|c|c|c|c|}
\hline Chrom. & Probe & BAC-contig & Genes \\
\hline 1 & -- & - & -- \\
\hline \multirow[t]{3}{*}{2} & BAC Ba 102 L1 & Contig 9 & $\begin{array}{l}\text { NF-kappa-B inhibitor cactus; DNA replication complex GINS protein PSF1; } \\
\text { Adenylosuccinate synthetase; Mitochondrial import inner membrane } \\
\text { translocase subunit Tim9; Novel protein coding; Enhanced at puberty } \\
\text { protein 1-like protein B; Microtubule-associated proteins 1AV1B light chain 3C. }\end{array}$ \\
\hline & $\mathrm{Ba} 177 \mathrm{C} 21$ & Contig 10 & $\begin{array}{l}\text { Novel protein coding; ADAMTS-like protein 3; F-box only protein 22; } \\
\text { Novel protein coding; Novel protein coding; }\end{array}$ \\
\hline & Ba50F9 & Contig 11 & MT-IIG (C. virginica), Filamin-A-like (C.gigas predicted) \\
\hline \multirow[t]{3}{*}{3} & $\mathrm{H} 4$ & -- & H4 histone \\
\hline & BAC Ba17L12 & Contig 5 & $\begin{array}{l}\text { Ribonuclease P protein subunit p40; Kelch-like protein 13; Sodium-and } \\
\text { chloride-dependent betaine transporter; Pleckstrin-like protein domain-containing } \\
\text { family B member 2; Proteasome subunit beta type-8; Novel protein coding; } \\
\text { Novel protein coding; Steroid 17-alpha-hydroxylase/17,20 lyase; } \\
\text { E3 ubiquitin-protein ligase MYLIP; Pyruvate dehydrogenase phosphatase } \\
\text { regulatory subunit, mitochondrial }\end{array}$ \\
\hline & BAC Ba18I16 & Contig 8 & $\begin{array}{l}\text { Kelch-like protein 13; Sodium-and chloride-dependent betaine transporter; } \\
\text { Pleckstrin-like protein domain-containing family B member 2; Proteasome } \\
\text { subunit beta type-8; Novel protein coding; Novel protein coding; Novel protein } \\
\text { coding; Steroid 17-alpha-hydroxylase/17,20 lyase; E3 ubiquitin-protein ligase } \\
\text { MYLIP; Pyruvate dehydrogenase phosphatase regulatory subunit, mitochondrial; }\end{array}$ \\
\hline \multirow[t]{2}{*}{4} & $5 S$ rDNA & -- & 5S Ribosomal DNA \\
\hline & BAC Ba10606 & Contig 1 & $\begin{array}{l}\text { Metallothionein; Novel protein coding; Filamin-C; Novel protein coding; Novel } \\
\text { protein coding; Nudix hydrolase 20; JmjC domain-containing protein C2orf60-like } \\
\text { protein; Novel protein coding; Novel protein coding; Tripartite motif-containing protein 3; } \\
\text { Neurogenic locus notch-like protein 4; Caveolin; Metallothionein; Metallothionein; }\end{array}$ \\
\hline \multirow[t]{2}{*}{5} & $5 S$ rDNA & -- & $5 S$ ribosomal DNA \\
\hline & BAC Ba3D14 & Contig 2 & $\begin{array}{l}\text { Myeloid differentiation primary response protein MyD88; Novel protein coding; } \\
\text { Myeloid differentiation primary response protein MyD88; Novel protein coding; } \\
\text { Myeloid differentiation primary response protein MyD88; Putative GTP-binding } \\
\text { protein 6; LIM domain and actin-binding protein 1; Novel protein coding; } \\
\text { Novel protein coding; Calcineurin-binding protein cabin-1; Di-N-acetylchitobiase. }\end{array}$ \\
\hline 6 & Ba127F5 & Unitig-Ba127F5 & $\begin{array}{l}\text { Serine/threonine-protein kinase 19; Protein Dom3Z; ZZ-type zinc finger-containing } \\
\text { protein 3; Rhodopsin, GQ-coupled; C3a anaphylatoxin chemotactic receptor; } \\
\text { Melatonin receptor type 1B; Melatonin receptor type 1B; G-protein coupled } \\
\text { receptor moody. }\end{array}$ \\
\hline \multirow[t]{2}{*}{7} & BAC Ba133H22 & Contig 3 & $\begin{array}{l}\text { Thyroid transcription factor } 1 \text {-associated protein 26; Orexin receptor type 2; } \\
\text { Novel protein coding; WD repeat-containing protein } 86 ; \text { WD repeat-containing protein } \\
86 ; \text { Novel protein coding; Novel protein coding; Cys-loop ligand-gated ionic channel. }\end{array}$ \\
\hline & BAC Ba96Р24 & Contig 6 & $\begin{array}{l}\text { Galanin receptor type 2; Alpha-2A adrenergic receptor; Thyroid transcription } \\
\text { factor 1-associated protein 26; Orexin receptor type 2; Novel protein coding; } \\
\text { Novel protein coding; Cys-loop ligand-gated ionic channel. }\end{array}$ \\
\hline \multirow[t]{2}{*}{8} & BAC Ba13P13 & Contig 4 & $\begin{array}{l}\text { Novel protein coding; Tripartite motif-containing protein 45; Complement } \\
\text { Clq-like protein 3; Tripartite motif-containing protein 45; NADH dehydrogenase } \\
\text { [ubiquinone] } 1 \text { beta subcomplex subunit 11, mitochondrial; Novel protein coding; } \\
\text { Neurogenic locus notch-like protein 2; Putative imidazolonepropionase; Coiled-coil } \\
\text { domain-containing protein 37; Ribonuclease P protein subunit p30; Novel protein } \\
\text { coding; Tryptase gamma; Protein sidekick-2; Tyrosine-protein phosphatase 99A; } \\
\text { Metalloproteinase inhibitor 1; Tissue inhibitor of metalloproteinase TIMP; } \\
\text { Metalloproteinase inhibitor 3; Tissue inhibitor of metalloproteinase TIMP 1.1; } \\
\text { WD40 repeat-containing protein SMU1; N-acetyltransferase ats 1; Novel protein coding. }\end{array}$ \\
\hline & BAC Ba45B21 & Contig 7 & $\begin{array}{l}\text { Myeloid differentiation primary response protein MyD88; Novel protein coding; } \\
\text { Heavy metal-binding protein HIP; Myeloid differentiation primary response protein } \\
\text { MyD88; Novel protein coding; Myeloid differentiation primary response protein } \\
\text { MyD88; Thioredoxin-like protein 4A; Putative GTP-binding protein 6; LIM domain } \\
\text { and actin-binding protein 1; Novel protein coding; Novel protein coding; } \\
\text { Disrupted in renal carcinoma protein 2-like protein }\end{array}$ \\
\hline 9 & -- & -- & -- \\
\hline 10 & $18 S$ rDNA & -- & 185 ribosomal DNA \\
\hline
\end{tabular}

BACs in bold were hybridized by means of 2-color and multiple-color BAC-FISH technique 


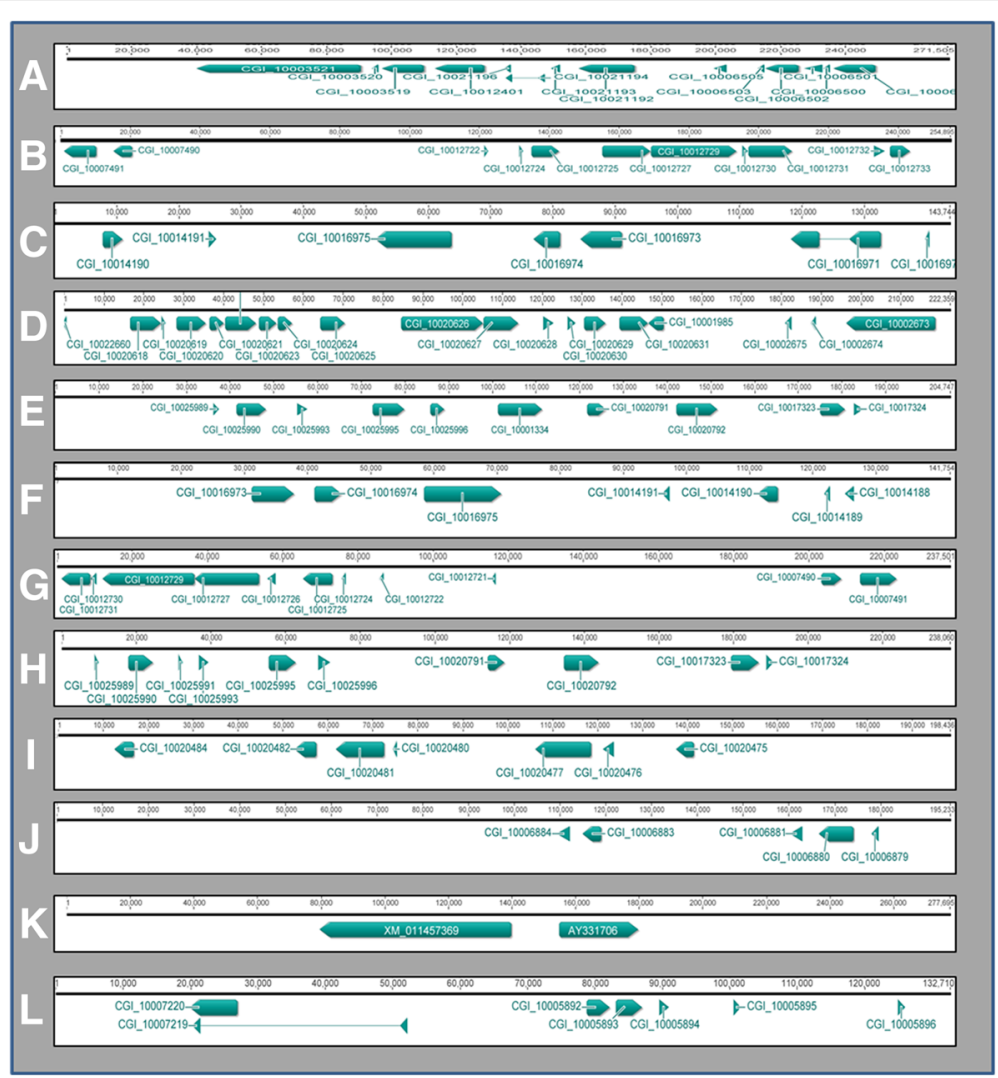

Fig. 2 Annotation of C. gigas BAC-contigs. Genes are indicated by arrows and are labeled with the ID of genes as named in the C. gigas genome database. A-K correspond to BAC-contigs 1-11 respectively. L corresponds to BAC127F5

\section{Annotation and integrated genetic map}

Following the bioinformatic analysis carried out to annotate BAC-contigs, 88 genes were annotated in the BAC-contigs and mapped in Crassostrea chromosomes. In Table 2, Figure 2 and Additional file 2: Table S2, all the information about gene annotation is shown. Figure 3 shows the integrated map obtained after BAC-FISH and annotation analysis.

Results show that contig- 1 arises from the assembly of eight BACs and it is $271,505 \mathrm{bp}$ long (Table 1; Additional file 1: Table S1). This contig-1 is located in chromosome 4 and presents 14 genes, including 3 metallothionein genes $(M T)$ and 5 novel protein codings, which are predicted genes described in the $C$. gigas Ensemble Metazoa database as being of unknown function.

Contig-2 is located in chromosome 5; it is $254,895 \mathrm{bp}$ long (Table 1; Additional file 1: Table S1) and it contains 11 genes, four of them with unknown function. Some of the genes are associated with the myeloid differentiation primary response protein. Genes for calcineurin-binding protein cabin-1 and acetylchitobiose are also present.

Contig-3 results from the assembly of two BACs: Ba133H22 and Ba183L3. The former was used as probe in the FISH analysis. Since this contig presented a wide region of non-homologies between the two BACs, the annotation was made mainly based on the BAC hybridized. After annotations, it can be seen that contig-3 includes 7 genes including a thyroid transcription factor and an orexin receptor. Three genes with unknown function are also found.

Contig- 4 emerges from the assembly of 5 BAC sequences and has a length of 222,359 bp (Table 1; Additional file 1: Table S1). From the five BACs included in this contig, the BAC named Ba13P13 was used as a probe. Contig-4 includes the largest number of genes of all contigs analyzed. It contains 19 genes; four of them are novel protein genes. The 15 genes with known function include metalloproteinase inhibitor 1, tissue inhibitor of metalloproteinase (TIMP) and acetyltransferase (ats1), among others. Contig 4 is located in chromosome 8.

Contig- 5 arises from the assembly of four BACs and it is 204,747 bp long (Table 1; Additional file 1: Table S1). To locate the contig in chromosomes of the two oyster species, BAC Ba17L12 was used as a probe. It localizes in chromosome 3 (Figs. 1 and 2). This contig has annotated 10 genes including ubiquitin-protein ligase MYLIP, pyruvate dehydrogenase phosphatase regulatory subunit, and sodium and chloride-dependent betaine transporter, 


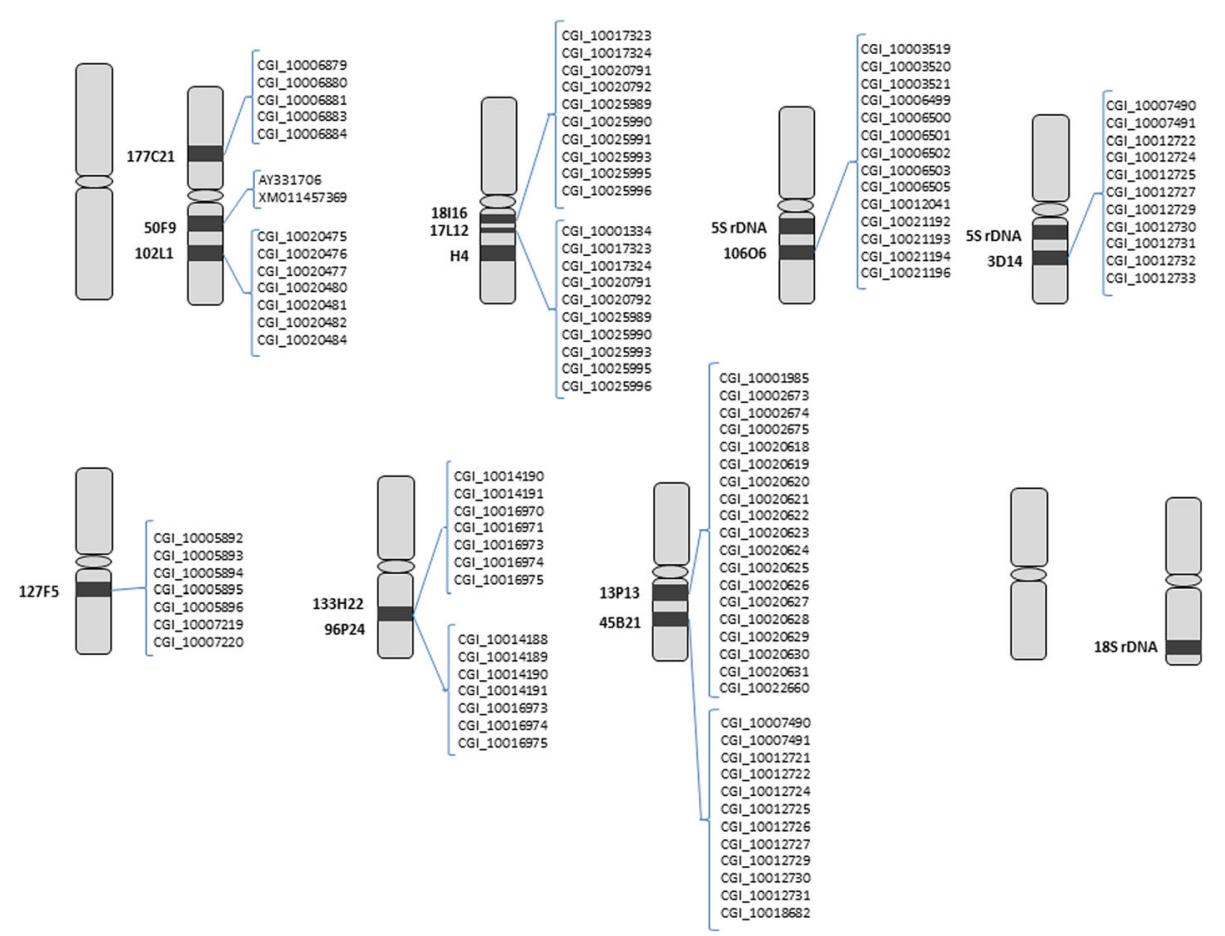

Fig. 3 Integration of physical and cytogenetic maps of Crassostrea angulata/gigas. Cytogenetic results are shown in black boxes within the chromosome diagram. Labels indicate the ID of genes as named in the C. gigas genome database

among others. Two genes of unknown function were also annotated (Table 2; Additional file 1: Tables S1 and Additional file 2 Table S2).

Contig-6 includes 3 BAC sequences and it is $141,754 \mathrm{bp}$ long (Table 1; Additional file 1 Table S1). BAC Ba96P24 was used as a probe to localize the contig and it hybridized in chromosome 7. The annotations of this contig showed that it contains 7 genes, five of them with known functions. Several of the genes, such as thyroid transcription factor, orexin receptor type 2 and cys-loop ligand-gated ionic channel genes, are also present in contig 3 , but others like galanin receptor type 2 and alpha- $2 A$ adrenergic receptor, are not. Contig-3 is also present in chromosome 7 and co-localizes with this contig-6.

Contig-7 is 237,501 bp long (Table 1; Additional file 1: Table S1) and it emerges from 3 BACs sequences. It includes 12 genes, eight of them with functions including heavy metal-binding protein, thioredoxin-like protein $4 \mathrm{~A}$ and actin-binding protein 1. Like contig-4, it localizes in chromosome 8.

Contig- 8 comes from the assembly of two BAC sequences, Ba18I16 and Ba8F15, and it is 238,060 bp long (Table 1; Additional file 1: Table S1). The Ba18I16 BAC was used as a probe to localize it in chromosomes of the oysters C. angulata and C. gigas. Contig-8 co-localizes with contig-5 in chromosome 3 . Genes annotated are the same in both contigs, except for ribonuclease P protein subunit 440 , which is absent in contig-8.
Chromosome 2 showed a hybridization signal with 3 BACs, corresponding to three contigs: contig-9, 10 and 11. Contig-9 results from the assembly of 3 BAC sequences, and is 198,436 bp long (Table 1; Additional file 1: Table S1). The annotation of contig-9 showed 6 genes with known function and 1 novel protein coding. Among the six genes can be found DNA replication complex GINS protein PSF1, adenylosuccinate synthetase, and microtubule-associated proteins $1 \mathrm{~A} / 1 \mathrm{~B}$ light chain $3 \mathrm{C}$. Contig-10 is 195,233 bp long and arises from two BACs (Table 1; Additional file 1: Table S1). It has 5 genes, but only two of them (ADMAMTS-like protein and F-box protein 22) with known function. Contig-11 did not show a match with any genes annotated in the NCBI C. gigas database, so it was BLAST-searched against the nucleotide collection $(\mathrm{nr} / \mathrm{nt})$ and filtered for mollusks in the NCBI database. Two genes were found: metallothionein (C. virginica IIG) and filamin-A-like (C. gigas predicted).

The unitig BAC Ba127F5 is 132,710 bp long and it has 6 genes and one novel protein coding (Tables 1 and 2; Additional file 1: Table S1). Included in this BAC are the galanin receptor type 2 , orexin receptor type 2 , and cys-loop ligand-gated ionic channel genes.

The GO analysis showed that most genes in BAC-contigs showed Molecular Functions (GO term category) related to protein binding. In particular, we have observed an enrichment in the GO terms "metal ion binding" and "zinc ion binding" in most BAC-contigs: 1, 2, 5, 7-11 and unitig 
BAC 127F5 (Table 3; Additional file 3: Table S3; Additional file 4: Figure S1). Other functions include "hydrolase activity" (BAC-contigs 2 and 4), "GTP binding" (2, 7 and 9) or "G-protein coupled receptor activity" (BAC-contigs 3, 6 and BAC-unitig) were also enriched (Table 3).

\section{Genomic structure of BAC-contigs}

The structure of the BAC-contigs, obtained after gene annotations, and the information about $C$. gigas gene order obtained from the Genomicus database, were compared. After testing concordance between the BAC-contigs structure and the scaffold assembly available in the C. gigas genome database (Table 4; Additional file 5: Figure S2), it was observed that most of the BAC-contigs structure were not concordant with the gene structure of the C. gigas scaffolds displayed in the Genomicus database. BAC-contig 1 presented 15 genes belonging partially to 4 scaffolds displayed in the Genomicus database, and they were incompatible with each other (Table 3; Additional file 4: Figure S1). BAC-contig 2 contains 11 genes and their relative position and genetic structure were not comparable to what is observed in the scaffolds of the Genomicus databases, where genes were found in partial regions of scaffold 870 and scaffold 617. BAC-contigs 3, 4, 5, 7, 8 and BAC 127F5 also presented scaffold incompatibility, being contained in a range of 2-4 incompatible scaffolds. Only in scaffolds 6, 9 and 10 could be observed a genetic structure compatible with scaffolds from the $C$. gigas genome databases, because genes annotated were present in single or several compatible scaffolds.

\section{Discussion}

FISH has been proved to be an efficient method for correlating genetic and cytogenetic maps using marker-anchored BAC clones [18].

In the cytogenetic map of $C$. angulata and $C$. gigas oysters, following our results, we were able to identify 8 out of 10 chromosome pairs using BAC clones as probes. These results are relevant because the karyotype of the Crassostrea species presents a small range of morphology and sizes $[10,28]$, and it has not been possible to identify every one. In the oysters $C$. angulata and C. gigas, $5 \mathrm{~S}$ rDNA genes are located in chromosomes 4 and $5[28,45]$ and the 5.8-18-28S rDNA genes in chromosome $10[15,46]$. Our results show that chromosomes 4 and 5 can be identified by the position of $\mathrm{Ba} 106 \mathrm{O} 6$ and Ba3D14 BAC clones. In relation to the $\mathrm{H} 4$ histone gene, when using BAC-FISH conditions, this gene was observed in chromosome pair 3. However, after using standard FISH protocols that are usually applied to multigene families [28], a second signal was detected in a medium-size chromosome. In C. gigas the location of the $\mathrm{H} 3$ gene has been described [42], but the position described is not consistent with our findings, since those authors described two hybridization signals on chromosome pairs 4 and 10 . It could be argued that the position 3 observed in our results is different from chromosome pair 4, owing to an absence of chromosomal markers in that work leading to a mistake being made between the two chromosome pairs (3 and 4) that are almost identical in size and morphology. Our results

Table 3 Summary of the top 4 Go Term per contig (Molecular Function Category)

\begin{tabular}{ll}
\hline Contig & Gene onthology term \\
\hline Contig 1 & GO:0005515, GO:0000049, GO:0016706, GO:0046872 \\
Contig 2 & GO:0005515, GO:0004553, GO:0005525, GO:0008270 \\
Contig 3 & GO:0004930, GO:0004983, GO:0005230, GO:0005515 \\
Contig 4 & GO:0005515, GO:0016787, GO:0016810, GO:0016812 \\
Contig 5 & GO:0005515, GO:0008270, GO:0004175, GO:0004298 \\
Contig 6 & GO:0004930, GO:0004983, GO:0005230 \\
Contig 7 & GO:0005515, GO:0005525, GO:0008270 \\
Contig 8 & GO:0005515, GO:0008270, GO:0004175, GO:0004298 \\
Contig 9 & GO:0000287, GO:0004019, GO:0005525, GO:0046872 \\
Contig 10 & GO:0005515, GO:0008233, GO:0008237, GO:0008270 \\
Contig 11 & GO:0051015, GO:0005515, GO:0046872 \\
BAC 127F5 & GO:0004930, GO:0003677, GO:0008270, GO:0016301
\end{tabular}
Go term description

Protein binding, tRNA binding, oxidoreductase activity, metal ion binding.

Protein binding, hydrolase activity, GTP binding, zinc ion binding.

G-protein coupled receptor activity, neuropeptide $Y$ receptor activity, extracellular ligand-gated ion channel activity, protein binding.

Protein binding, hydrolase activity, acting on carbon-nitrogen (but not peptide) bonds, hydrolase activity, acting on carbon-nitrogen (but not peptide) bonds, in cyclic amides.

Protein binding, zinc ion binding, endopeptidase activity, threonine-type endopeptidase activity.

G-protein coupled receptor activity, neuropeptide Y receptor activity, extracellular ligand-gated ion channel activity.

Protein binding, GTP binding, zinc ion binding.

Protein binding, zinc ion binding, endopeptidase activity, threonine-type endopeptidase activity.

Magnesium ion binding, adenylosuccinate synthase activity, GTP binding, metal ion binding.

Protein binding, peptidase activity, metallopeptidase activity, zinc ion binding. 
Table 4 Comparative analysis between genes annotated in BAC-contigs and scaffolds, from C. gigas genome database, where they would be contained

\begin{tabular}{llll}
\hline BAC-Contig & Number of genes & $\begin{array}{l}\text { Number of scaffolds } \\
\text { (C. gigas genome database) }\end{array}$ & Scaffold ID \\
\hline 1 & 15 & 4 & Scaffold1297, scaffold852, scaffold99, scaffold1121. \\
2 & 11 & 2 & Scaffold870, scaffold617 \\
3 & 7 & 2 & Scaffold631, scaffold117 \\
4 & 19 & 4 & Scaffold1360, scaffold410, scaffold244, scaffold38210 \\
5 & 10 & 4 & Scaffold425, scaffold34732, scaffold1004, scaffold 1900 \\
6 & 7 & 2 & Scaffold117, scaffold631 \\
7 & 12 & 3 & Scaffold617, scaffold189, scaffold870 \\
8 & 10 & 3 & Scaffold425, scaffold1004, scaffold1900 \\
9 & 7 & 1 & Scaffold388 \\
10 & 5 & 1 & Scaffold2448 \\
11 & 2 & - & ND \\
BAC127F5 & 7 & 2 & Scaffold42558, scaffold41988 \\
\hline
\end{tabular}

show that the position is not in chromosome 4 as described by Boully et al. [42], because that position is occupied by $5 \mathrm{~S}$ rDNA genes [28, 45]. However an even more relevant result is that histone genes are not in chromosome 10 [42], because that is the chromosome that bears major ribosomal genes described in the Pacific and Portuguese oysters $[15,46]$, and the double FISH carried out in this study confirms that the two families are not co-localized. For that reason, the location of the histone genes should be revised because contradictory results have been obtained in those experiments.

The GO term analysis showed an over-representation in BAC-contigs of molecular function associated with metal ion binding and zinc ion binding. In previous studies, enrichment was found in genes coding for proteins implicated in the detoxification of metal ions in polluted areas, in C. angulata, in comparison with those of $C$. gigas [37]. In this work we have localized a metallothionein gene in chromosome 2 and 4, in the BAC-contig 1. Metallothioneins (MTs) are a superfamily of ubiquitously-expressed metal-binding proteins that can be upregulated by exposure to metal, oxidative stress and immune system challenge [47, 48]. MTs are well-known small, cystein-rich proteins that have the ability to bind with high affinity to heavy metal ions, and whose synthesis is regulated by concentrations of metals [49]. MTs play roles in the metabolism of non-toxic essential metals (zinc and copper), as well as toxic heavy metals (cadmium, mercury, etc) [50]. Species of the genus Crassostrea have been used in ecotoxicological bioassays to assess the bioaccumulation of $\mathrm{Cd}$ and $\mathrm{Zn}$ in field conditions [51] and in transplant assays $[52,53]$. When comparing the genome of $C$. angulata with that of $C$. gigas, the GO terms (which describe molecular function) associated with binding to ions of zinc and other metals present in C. angulata account for the largest number of polymorphic genes (Single nucleotide polymorphisms: SNP) observed [37]. In that context the location of MT genes in Crassostrea gigas/ angulata genome represents an important advance in the study of those genes in relation to chromosome mapping.

In this work we have assembled BAC sequences available in the GeneBank database of the C. gigas oyster and obtained BAC-contig sequences longer than BAC sequences. This approach has allowed us to annotate larger regions than can be done at the level of BACs, and provides knowledge of larger regions of the genome. After annotation we have elucidated the structure of BAC-contigs and, after comparison with the scaffolds of the $C$. gigas genome database, a large number of inconsistencies have been revealed. In many cases, several genes belonging to the same BAC-contigs were mapped in partial regions of different scaffolds in the $C$. gigas database. The main consequence is that a substantial fraction of the genome scaffolds reported by Zhang et al. [40] are incorrectly assembled. These results are in line with those previously published by Hedgecock et al. [38], who after making second-generation linkage maps, with SNP markers, for the Pacific oyster C. gigas, observed that more than $38 \%$ of the scaffolds with two or more SNPs contained SNPs that unexpectedly map to two or more linkage groups. In our study it is observed that the more genes per BAC-contig, the more scaffolds to which contigs map. Thus, the higher the level of assembly, the greater the number of mistakes (i.e. mis-assemblies) that are made. In C. gigas, it has been reported previously that classifying scaffolds by the number of SNPs they contain and by the number of linkage groups to which they map reveals a highly significant, positive association between the two factors. Our data reinforce previous results that claim that misassembled scaffolds comprise large 
blocks, with the implication that, if the ordering of contigs and genes within scaffolds cannot always be accurate, results about the clustering of gene families, like Hox genes [54], should be regarded as provisional until the assembly of genome scaffolds is either confirmed or improved [38]. Currently, the $C$. gigas genome (oyster assembly v9) is assembled to scaffold level and more than 7000 scaffolds are presented [40]. The use of this technique in other species of shellfish and oysters will open a huge potential for direct and fast analysis of genomes in species of high commercial value.

\section{Conclusions}

Molecular markers for 8 out 10 chromosomes have been developed in Crassostrea angulata/gigas that allow the differentiation of all chromosomes in the species. An integrated genetic map anchored to the genome has been obtained. Important genes related to resistance to abiotic stress have been mapped.

\section{Additional files}

Additional file 1: Table S1. Summary of BAC-contigs statistics. (DOCX $13 \mathrm{~kb}$ )

Additional file 2: Table S2. Data of BAC-contigs annotations. (XLSX 19 kb)

Additional file 3: Table S3. Summary of Gene Ontology term enrichment statistics. (XLSX $2457 \mathrm{~kb}$ )

Additional file 4: Figure S1. Comparison chart of significant Gene Ontology terms of genes located in BAC-contigs. The arrows indicate the relationship among the $\mathrm{GO}$ categories. Colored boxes indicate enriched Gene Ontology terms found in the study. (PDF $2475 \mathrm{~kb}$ )

Additional file 5: Figure S2. Comparative analysis of genomic structure of BAC-contig and Genomicus browser. (PDF $356 \mathrm{~kb}$ )

\section{Acknowledgments \\ The authors acknowledge their gratitude to the Ensemble team and Genomicus Browser curators for providing a browser and database that greatly facilitated the use and analyses of the BACs used in this work. We also thank all the institutions, consortium leaders, coordinators, and supervisors of genome projects that have made genome information available.}

\section{Funding}

This study has been supported by the AQUAGENET project (SOE 2/ P1/E287) from the INTERREG IVB SUDOE program and by grants from the Junta de Andalucía (Spain) to the PAI BIO-219 group. The role of the funding bodies is limited to direct funding of the project activities in the field and laboratory that results in this manuscript.

\section{Availability of data and materials}

The data that support the findings of this study are available in the supplementary materials.

\section{Authors' contributions}

IC carried out the bioinformatic analysis of BAC clones, the 2-color FISH, and drafted the manuscript. SP and TL carried out the $\mathrm{MFISH}$. AM participated in the sequence analysis and helped to draft the manuscript. AG and MER and carried out the sampling, tissue extraction, chromosome preparations and contributed to the FISH analysis. LR conceived and coordinated the study, participated in its design, discussed the results and corrected the manuscript. All authors read and approved the final manuscript.
Ethics approval and consent to participate

Not applicable. The animals studied in this work are bivalve mollusks, noncephalopod invertebrates. No field permissions were required to obtain these samples for the research.

\section{Consent for publication}

Not applicable

\section{Competing interests}

The authors declare that they have no competing interests.

\section{Publisher's Note}

Springer Nature remains neutral with regard to jurisdictional claims in published maps and institutional affiliations.

\section{Author details}

${ }^{1}$ Area de Genética. Facultad de Ciencias del Mar y Ambientales, Universidad de Cádiz. Polígono Río San Pedro, 11510 Puerto Real, Cádiz, Spain. ${ }^{2}$ Institut für Humangenetik, Universitätsklinikum Jena, 07743 Jena, Germany.

Received: 10 April 2018 Accepted: 30 October 2018

Published online: 15 November 2018

References

1. Food and Agriculture Organization of the United Nations, FAO. 2016. http://www.fao.org/fishery/statistics/en.

2. Wang Y, Guo X. ITS length polymorphism in oysters and ITS use in species identification. J Shellfish Res. 2008;27(3):489-93.

3. Wang H, Quian L, Liu X, Zhang G, Guo X. Classification of a common cupped oyster from southern China. J Shellfish Res. 2010;29(4):857e66.

4. Langdon C, Evans F, Jacobson D, Blouin M. Yields of cultured Pacific oysters Crassostrea gigas Thunberg improved after one generation of selection. Aquaculture. 2003;220:227-44.

5. Hedgecock D, Davis JP. Heterosis for yield and crossbreeding of the Pacific oyster Crassostrea gigas. Aquaculture. 2007;272(Supplementary 1):S17-29.

6. Dégremont L, Bédier E, Boudry P. Summer mortality of hatchery-produced Pacific oyster spat (Crassostrea gigas). II. Response to selection for survival and its influence on growth and yield. Aquaculture. 2010;299:21-9.

7. Hedgecock D, Gaffney PM, Goulletquer P, Guo X, Reece K, Warr GW. The case for sequencing the Pacific oyster genome. J Shellfish Res. 2005;24:429-41.

8. Curole JP, Hedgecock D. Bivalve genomics: complications, challenges, and future perspectives. In: Liu ZJ, editor. Aquaculture Genome Technologies. Ames, lowa: Blackwell publishing; 2007. p. 525-43.

9. Wang J, Li L, Zhang G. A high-density SNP genetic linkage map and QTL analysis of growth-related traits in a hybrid family of oysters (Crassostrea gigas $x$ Crassostrea angulata) using genotyping-by-sequencing. G3 (Bethesda). 2016;6(5):1417-26.

10. Thiriot-Quiévreux C. Review of the literature on bivalve cytogenetics in the last ten years. Cah Biol. 2002;43:17-26.

11. Michinina S, Rebordinos L. Genetic differentiation in marine and estuarine natural populations of Crassostrea angulata. Mar Ecol Prog Ser. 1997;154:167-74.

12. Insua A, Thiriot-Quiévreux C. Karyotype and nucleolus organizer regions in Ostrea puelchana (Bivalvia: Ostreidae). Veliger. 1993;36:215-9.

13. Li XX, Havenhand JN. Karyotype, nucleolus organiser regions and constitutive heterochromatin in Ostrea angasi (Molluscae: Bivalvia): evidence of taxonomic relationships within the Ostreidae. Mar Biol. 1997;127:443-8.

14. Thiriot-Quiévreux $C$, Insua A. Nucleolar organiser region variation in the chromosomes of three oyster species. J Exp Mar Biol Ecol. 1992;157:33-40.

15. Cross I, Vega L, Rebordinos L. Nucleolar organizing regions in Crassostrea angulata: Chomosomal location and polymorphism. Genetica. 2003;119:65-74.

16. Leitão A, Chaves R, Santos S, Guedes-Pinto H, Boudry P. Restriction enzyme digestion chromosome banding in Crassostrea gigas, Crassostrea angulata. Ostrea edulis and Ostrea conchaphila Comparative karyological analysis within Ostreidae Genome. 2004:47:781-8.

17. Leitão A, Chaves R, Santos R, Guedes-Pinto H, Boudry P. Interspecific hybridisation in oysters: restriction enzyme digestion chromosome banding confirms Crassostrea angulata $\times$ Crassostrea gigas F1 hybrids. J Exp Mar Biol Ecol. 2007:343:253-60.

18. Feng L, Hu L, Fu X, Liao H, Li X, Zhan A, et al. An integrated genetic and cytogenetic map for Zhikong scallop, Chlamys farreri, based on microsatellite markers. PLoS One. 2014;9(4):e92567. 
19. Yoshido A, Bando H, Yasukochi Y, Sahara K. The Bombyx mori karyotype and the assignment of linkage groups. Genetics. 2005;170:675-85.

20. Huang Y, Zhao Y, Haley CS, Hu S, Hao J, Wu C, et al. A genetic and cytogenetic map for the duck (Anas platyrhynchos). Genetics. 2006;173(1):287-96.

21. Stratikopoulos EE, Augustinos AA, Petalas YG, Vrahatis MN, Mintzas A, Mathiopoulos KD, et al. An integrated genetic and cytogenetic map for the Mediterranean fruit fly, Ceratitis capitata, based on microsatellite and morphological markers. Genetica. 2008;133:147-57.

22. Ren Y, Zhang ZH, Liu JH, Staub JE, Han YH, Cheng Z, et al. An integrated genetic and cytogenetic map of the cucumber genome. PLoS One. 2009;4(6):e5795.

23. Portela-Bens S, Merlo MA, Rodríguez ME, Cross I, Manchado M, Kosyakova N, et al. Integrated gene mapping and synteny studies give insights into the evolution of a sex proto-chromosome in Solea senegalensis. Chromosoma. 2017;126:261-77.

24. Phillips RB, Amores A, Morasch MR, Wilson C, Postlethwait JH. Assignment of zebrafish genetic linkage groups to chromosomes. Cytogenet Genome Res. 2006;114:155-62.

25. Úbeda-Manzanaro M, Merlo MA, Palazón JL, Cross I, Sarasquete C, Rebordinos L. Chromosomal mapping of the major and minor ribosomal genes, (GATA)n and U2 snRNA gene by double-colour FISH in species of the Batrachoididae family. Genetica. 2010;138:787-94.

26. García-Cegarra A, Merlo MA, Ponce M, Portela-Bens S, Cross I, Manchado M, et al. Preliminary genetic map in Solea senegalensis (Pleuronectiformes, Soleidae) using BAC-FISH and next-generation sequencing. Cytogenet Genome Res. 2013;141:227-40.

27. Taboada X, Pansonato-Alves JC, Foresti F, Martínez P, Viñas A, Pardo BG, et al. Consolidation of the genetic and cytogenetic maps of turbot (Scophthalmus maximus) using FISH with BAC clones. Chromosoma. 2014; 123:281-91.

28. Cross I, Díaz E, Sánchez I, Rebordinos L. Molecular and cytogenetic characterization of Crassostrea angulata chromosomes. Aquaculture. 2005; 247:135-44.

29. López-Flores I, Ruiz-Rejón C, Cross I, Rebordinos L, Robles F, Navajas-Pérez R, et al. Molecular characterization and evolution of an interspersed repetitive DNA family of oysters. Genetica. 2010;138:1211-9.

30. Bouilly $K$, Chaves R, Leitão A, Benabdelmouna A, Guedes-Pinto $H$. Chromosomal organization of simple sequence repeats in the Pacific oyster (Crassostrea gigas): (GGAT)(4), (GT)(7) and (TA)(10) chromosome patterns. J Genet. 2008;87(2):119-25.

31. Wang $Y, X u Z$, Guo X. Differences in the rDNA-bearing chromosome divide the Asian-Pacific and Atlantic species of Crassostrea (Bivalvia, Mollusca). Biol Bull. 2004;206:46-54.

32. Doenecke D, Albig W, Bode C, Drabent B, Franke K, Gavenis K, et al. Histones: genetic diversity and tissue-specific gene expression. Histochem Cell Biol. 1997;107(1):1-10.

33. Armbruster GFJ, Böhme M, Bernhard D, Schlegel M. The H3/H4 histone gene cluster of land snails (Gastropoda: Stylommatophora): TS/TV ratio, GC3 drive and signals in stylommatophoran phylogeny. J Mollusc Stud. 2005; 71(4):339-48.

34. González -RR, Ausió J, Méndez J, Eirín-López JM. Early evolution of histone genes: prevalence of an "Orphon" $\mathrm{H} 1$ lineage in protostomes and birth-anddeath process in the H2A family. J Mol Evol. 2008;66(5):505-18.

35. Oskars TR, Bouchet P, MAE M. A new phylogeny of the Cephalaspidea (Gastropoda: Heterobranchia) based on expanded taxon sampling and gene markers. Mol Phylogenet Evol. 2005;89:130-50.

36. Combosch DJ, Giribet G. Clarifying phylogenetic relationships and the evolutionary history of the bivalve order Arcida (Mollusca: Bivalvia: Pteriomorphia). Mol Phylogenet Evol. 2016;94:298-312.

37. Cross I, Merlo MA, Rodríguez ME, Portela-Bens S, Rebordinos L. Adaptation to abiotic stress in the oyster Crassostrea angulata relies on genetic polymorphisms. Fish Shellfish Inmunol. 2014;41:618-24.

38. Hedgecock D, Shin G, Gracey AY, Den Berg DV, Samanta MP. Secondgeneration linkage maps for the Pacific oyster Crassostrea gigas reveal errors in assembly of genome scaffolds. G3 (Bethesda). 2015;5(10):2007-19.

39. Wang Y, Xu Z, Pierce JC, Guo X. Characterization of eastern oyster (Crassostrea virginica Gmelin) chromosomes by fluorescence in situ hybridization with bacteriophage P1 clones. Mar Biotechnol. 2005;7:207-14.

40. Zhang G, Fang X, Guo X, Li L, Luo R, Xu F, et al. The oyster genome reveals stress adaptation and complexity of shell formation. Nature. 2012;490(7418):49-54.
41. Mazzuchelli J, Kocher TD, Yang F, Martins C. Integrating cytogenetics and genomics in comparative evolutionary studies of cichlid fish. BMC Genomics. 2012;13:463.

42. Bouilly $\mathrm{K}$, Chaves $\mathrm{R}$, Fernandes M, Guedes-Pinto H. Histone $\mathrm{H} 3$ gene in the Pacific oyster, Crassostrea gigas Thunberg, 1793: molecular and cytogenetic characterisations. Comp Cytogenet. 2010;4(2):111-21.

43. Lewis SE, Searle SM, Harris N, Gibson M, Lyer V, Richter J, et al. Apollo: a sequence annotation. Genome Biol. 2002;3:0082.

44. Louis A, Nguyen NTT, Muffato M, Crollius HR. Genomicus update 2015: KaryoView and MatrixView provide a genome-wide perspective to multispecies comparative genomics. Nucleic Acids Res. 2015;43:682-9.

45. Benabdelmouna A, Nadolna K, Ledu C. Fluorescence In Situ hybridization (FISH) of rDNA genes (5S and 18-5.8-28S) as a tool for chromosomal tagging and to assess the occurrence of somatic and sperm aneuploidy in Pacific oyster Crassostrea gigas. XVI Plant and Animal Genome Conference (PAG). 2008; http://archimer.ifremer.fr/doc/00000/3502/.

46. Xu Z, Guo X, Gaffney PM, Pierce JC. Chromosomal location of the major ribosomal RNA genes in Crassostrea virginica and Crassostrea gigas. Veliger. 2001:44(1, 2):79-83.

47. Jenny MJ, Ringwood AH, Schey K, Warr GW, Chapman RW. Diversity of metallothioneins in the American oyster, Crassostrea virginica, revealed by transcriptomic and proteomic approaches. Eur J Biochem. 2014;271:1702-12.

48. Jenny MJ, Payton SL, Baltzegar DA, Lozier JD. Phylogenetic analysis of molluscan Metallothioneins: evolutionary insight from Crassostrea virginica. J Mol Evol. 2016;83(3):110-25.

49. Kojima Y, Metallothionein KJHR. Trends Biochem Sci. 1978;3:90-3.

50. Tanguy A, Moraga D. Cloning and characterization of a gene coding for a novel metallothionein in the Pacific oyster Crassostrea gigas (CgMT2): a case of adaptive response to metal-induced stress? Gene. 2001;273:123-30.

51. Rebelo MF, Amaral MCR, High Zn PWC. Cd contamination in oyster from a contaminated coastal lagoon and its role in contamination assessment. Mar Pollut Bull. 2003:46:1354-8.

52. Amaral MCR, Rebelo MF, Torres JPM, Pfeiffer WC. Bioaccumulation and depuration of $\mathrm{Zn}$ and $\mathrm{cd}$ in mangrove oysters (Crasssotrea rhizophorae, Guilding, 1828) transplanted to and from a contaminated tropical coastal lagoon. Mar Environ Res. 2005;59:277-85.

53. Macías-Mayorga D, Laiz I, Moreno-Garrido I, Blasco J. Is oxidative stress related to cadmium accumulation in the Mollusc Crassostrea angulata? Aquat Toxicol. 2015;161:231-41.

54. Paps J, Xu F, Zhang G, Holland PW. Reinforcing the egg-timer: recruitment of novel lophotrochozoa homeobox genes to early and late development in the Pacific oyster. Genome Biol Evol. 2015;7(3):677-88.
Ready to submit your research? Choose BMC and benefit from:
- fast, convenient online submission
- thorough peer review by experienced researchers in your field
- rapid publication on acceptance
- support for research data, including large and complex data types
- gold Open Access which fosters wider collaboration and increased citations
- maximum visibility for your research: over $100 \mathrm{M}$ website views per year
At BMC, research is always in progress.
Learn more biomedcentral.com/submissions 